\title{
Breve relato da evolução da Revista Brasileira de Fisioterapia nos últimos anos
}

Em seus dez anos de existência, a Revista Brasileira de Fisioterapia- RBF passou por diversas mudanças. Entretanto, nos últimos anos estas mudanças foram mais evidentes e, acima de tudo, refletiram o grande avanço conquistado pela RBF, com apoio de toda comunidade científica. Esta evolução significativa merece ser ressaltada neste editorial:

Periodicidade: A RBF passou da periodicidade semestral para quadrimestral em 2002, e de quadrimestral para trimestral em 2006;

Indexações: A RBF foi indexada no LILACS em 2000, no SportDISCUS em 2003, no Cambridge Scientific Abstracts em 2004 e no SciELO em 2006. Encontra-se em processo de análise no CINAHL e poderá ser re-submetida para indexação no Medline;

Infra-estrutura: $\mathrm{O}$ espaço físico da RBF foi ampliado, contando atualmente com $53 \mathrm{~m}^{2}$ e deverá ser ampliado novamente quando mudar para um outro prédio que está sendo reformado. Neste prédio ocuparemos $96,08 \mathrm{~m}^{2}$. Três novos computadores foram adquiridos, duas impressoras e um scanner. O último projeto do CNPq permitiu a aquisição de um servidor para a implantação do sistema eletrônico de submissão de artigos;

Pessoal: A RBF conta atualmente com uma secretária executiva e duas bolsistas da UFSCar. A secretária executiva e uma das bolsistas receberam treinamento no Sistema de Editoração Eletrônico de Revistas SEER, oferecido pelo IBICT, para implantação do sistema eletrônico de submissão de manuscritos, que deverá ser implantado brevemente;

Normatização: A partir de 2002 a RBF adotou o estilo Vancouver;

Regularidade: A RBF tem sido publicada regularmente nos últimos sete anos;

Financiamento: Nos últimos anos obtivemos apoio do CNPq por meio de dois projetos pessoais aprovados em chamadas de editoração científica, um deles está permitindo a implantação do sistema de editoração eletrônica de manuscritos. Um novo projeto foi submetido à FAPEMIG e ao CNPq em Julho e Agosto/2006, respectivamente. Com a indexação recente no SciELO, solicitaremos também apoio financeiro à FAPESP. O Centro de Ciências Biológicas e da Saúde e o Departamento de Fisioterapia oferecem pequeno apoio em verba de custeio. A partir de 2005 a RBF vem sendo apoiada financeiramente pelo CREFITO-3, o que permitiu a disponibilização de duas versões on-line: uma versão em inglês e outra em português. Todo o gerenciamento da verba da RBF é realizado pela Fundação de Apoio Institucional da UFSCar, que documenta, arquiva notas fiscais e todos os comprovantes e documentos e permite transparência na utilização dos recursos;

Processo de Revisão: Os processos de revisão encontram-se todos documentados e atualizados. O número de revisores foi elevado para três por manuscrito, com consulta ao editor da área em caso de necessidade de arbitragem para pareceres controversos. Os revisores passaram a receber os pareceres dos demais revisores. Esse foi um procedimento sugerido pelo Prof. Celso Carvalho da USP, para melhorar a visibilidade da revisão para os revisores do processo em questão. O roteiro de revisão foi aprimorado, tornando-se mais diretivo nos itens avaliados (agradecemos às Professoras da UFMG Marisa Cotta Mancini e Rosana Ferreira Sampaio, pela contribuição). Um novo roteiro para revisões sistemáticas e meta-análises está sendo elaborado também por essas professoras; 
Banco de Revisores: Cresceu vertiginosamente e encontra-se atualmente com 496 participantes ativos. Os revisores, em sua maioria possuem título de doutor, estão cadastrados no CNPq e estão distribuídos por áreas de especialidade e por regiões do país;

Corpo de Editores/Editores Associados: é amplo, possui projeção nacional e internacional (22\% dos editores associados são estrangeiros), é participativo e contribui regularmente com a política editorial por meio de reuniões virtuais e presenciais;

Artigos de Revisão: Submissão espontânea de artigos de revisão está temporariamente suspensa para permitir que artigos de autores de projeção internacional, que realmente tenham dado uma contribuição científica significativa sobre determinado tema, sejam publicados a convite. Esse é um exemplo da política editorial da RBF que visa melhorar a qualidade editorial do periódico, aumentando as suas chances para indexações internacionais. Embora revisões passivas ou opinativas não sejam aceitas pela RBF em nenhuma área, submissões serão aceitas para artigos de revisão sistemática e meta-análise. Num futuro próximo, publicaremos em detalhes as características a serem consideradas para a elaboração dos artigos de revisão sistemática e meta-análise;

Apoio aos Programas de Pós-Graduação: A RBF, periódico científico da área de Fisioterapia no Brasil indexado no SciELO, tem publicado artigos de pesquisadores de todos os Programas de Pós-graduação relacionados à área no país, bem como de áreas correlatas, e precisa continuar recebendo suporte de nossa comunidade científica.

Frente a esse panorama positivo, convidamos todos a participarem, com envolvimento crescente nas atividades da RBF!

\author{
Helenice Jane Cote Gil Coury \\ Sérgio Teixeira Fonseca \\ Tania de Fátima Salvini
}

Editores da Revista Brasileira de Fisioterapia 